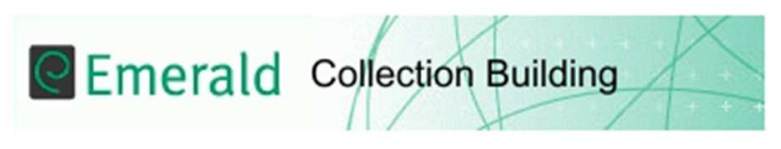

\title{
Current Trends in Collection Development Practices \& Policies
}

\begin{tabular}{|r|l|}
\hline Journal: & Collection Building \\
\hline Manuscript ID & CB-09-2016-0025 \\
\hline Manuscript Type: & Research Paper \\
\hline Keywords: & $\begin{array}{l}\text { collection development, trends, practices, policies, academic libraries, } \\
\text { survey }\end{array}$ \\
\hline \multicolumn{2}{|l}{} \\
\hline
\end{tabular}

SCHOLARONE

Manuscripts 
$\underline{\text { Introduction }}$

In today's knowledge economy, academic libraries are facing transformative challenges in regard to their role and activities - and collection development is no exception to this reality. Technological, educational, social, cultural, and economic drivers are having a significant impact on the practice of collection development. Exploring current attitudes to policies and practices, or rather policies in practice, is important to understanding current approaches, opportunities, and challenges. How do collections policies and practices co-exist in our libraries? What does this dynamic reveal about the state of innovation?

Our goal for this project is to provide a snapshot of new trends in collection development, based on a recent informal survey of selected libraries in North America (a mix of public and private institutions). The survey instrument is provided as an appendix to this paper. As a caveat we can emphasize that the results should not be seen as a comprehensive or definitive statement of new trends. Due to time constraints, we devised a survey and sent it out to only twenty librarians in North America who we knew to be actively engaged in national and international conversations about the future of collection development; we received sixteen responses. Our paper is based on these results.

In this survey we focus on several major themes: collection development policies; open access investment; demand-driven acquisition (DDA); budget issues; the Big Deal; rationalizing print collections; demonstrating value to our institutions; and perceived major trends in collection development. Not surprisingly, there are overlaps and relationships between these themes, as well as other collections issues that have peaked out from behind the curtains, as it were. It would certainly be valuable for someone to carry out a much fuller survey of these questions and themes, in order to determine how they can be understood on a much wider scale of practice in academic libraries.

\section{$\underline{\text { Collection Development Policies }}$}

Of the sixteen librarians that responded, five did not have collection development policies at all, and three others have transitioned in the last five years from an overly detailed policy to one that outlines general principles about collections. One library moved from a lengthy and cumbersome policy to one that states simply that the library supports the university's mission with its collections and does not censor. A few respondents indicated that the policies they used to have in place actually hindered them by being too specific. This move away from subjectlevel policies or away from policies entirely allows these libraries to be more nimble in responding to changes in focus for the university (such as toward interdisciplinary programs), to new types of resources (such as ebooks), or to new collection models (such as DDA).

All but one of the libraries in our sample have updated their collection development policies in the last five years. Four respondents stated that the revision was either to do away with a policy altogether or to simplify an overly prescriptive policy. Four indicated that the revision was 
entirely or partly because of the emergence of electronic content. Two mentioned DDA and two mentioned an emphasis on access over ownership. For one library open access was a reason for the revision.

All of the respondents felt that collection development practices at their library aligned with their policy. Those who had moved away from a detailed policy felt that this move had made this alignment possible. Interestingly, and in contradiction to most respondents, the one library without a recent revision to the policy said that because their policy presented a philosophy about collections it was easy to align with, but that it needed to be revised to add more detail so it could be used more strategically. In this context, we can cite the work of Rick Fought at the University of Tennessee regarding the role of the collection development policy: "A robust marketing program using every resource available, even the collection development policy, not only raises the visibility of the library, promotes use of the library collection, and better serves library patrons, but it also sends a clear message to campus administrators and other relevant stakeholders regarding the enduring value and worth of the library" (Fought, Gahn and Mills 176-177)

In this time of changing content types, emerging access models, expansion of collection practices, and development of interdisciplinary programs, it appears that policies have not always kept up. Several libraries operate without a policy at all, and several others have moved away from what they perceive as overly restrictive policies. Collection development policies should help librarians shape collections to meet institutional needs, and for some of these libraries the policies were getting in the way.

\section{Demand-Driven Acquisition (DDA)}

We were interested in discovering the extent to which these libraries use DDA, its impact on budget, and whether DDA was accounted for in collection development policies. It is worth noting Lorcan Dempsey's statement that, "we have seen a progressive move away from purchasing and local storage at one end of a spectrum toward general facilitated access at the other." (Dempsey, Malpas and Lavoie 397) Only one library in our sample does not use DDA, and most state that they use it quite heavily. Most use multiple vendors and models, and several do DDA through a consortium as well as locally.

In response to a question about the percentage of the collections budget dedicated to DDA, nine of the librarians stated that they were spending less than $5 \%$ annually, four reported 5$10 \%$, one $21-30 \%$, and one more than $30 \%$. So even though these librarians report heavy use of DDA, in most cases it still accounts for a relatively small amount of spending. It is a supplemental rather than fundamental practice for most of these libraries.

Perhaps not surprisingly given the relatively low impact of DDA on the budget, most respondents stated that DDA had not caused a shift in collection development policy. Two said that it had caused them to change their policy in some way. One stated that DDA was an outgrowth of their policy, which was based on meeting user needs. 
We asked our participants whether their libraries support Article Processing Charges (APCs) and other forms of open access investment strategies. Bjork and Solomon explain that "Funders are rightly concerned that the funding they provide for this purpose is well spent and that the APC funded OA market is transparent, competitive and reasonably priced. In a rapidly evolving market with a significant influx of funding, this is a very challenging problem" (Solomon and Bjork 7). Two-thirds of the respondents to this question (11/16) indicated that they support open access in one form or another. This is a reflection of the fact that open access has become a mainstream issue within many libraries in recent years, although the forms of support do vary significantly. We then asked about the amount of money that the library spends annually on open access investments. Nine respondents answered this question. The amounts ranged from quite small to very large - there were three that spend up to $\$ 20,000$ per year; two that spend \$20-60,000 per year; two that spend \$60-100,000 per year; and two that spend more than $\$ 100,000$ per year. This range is not surprising; it is a reflection of the fact that libraries have different financial circumstances and have prioritized open access investments in different ways, based on their complete set of priorities and drivers. We also wanted to know the source of open access funding - whether this was the collections budget, other library funding, or funding from the university (external to the library). Respondents were free to choose more than one answer. Nine chose the collections budget, three reported library funding other than the collections budget, and four stated that they had other funding from the university. While the collections budget is the primary source of financing of open access investments, other library funds and university funds were a source for some of the respondents. Six of the respondents selected more than one answer - this can be interpreted as meaning that open access is sometimes the result of multiple funding streams, depending on what is feasible within an institutional context, and perhaps indicating that universities have a hard time figuring out how to fund the transition to open access.

\section{Big Deals}

Despite years of controversy and challenge, the Big Deal is still prevalent today. This has drawn attention from various commentators. For example, Cleary notes that "Given spiralling price increases for serials and competing demands upon resource budgets, libraries have afforded Big Deals in a trend that cannot be sustained" (Cleary 377) while Bergstrom et al discovered that "Some institutions have been quite successful in bargaining for lower prices, whereas others may not have been aware that better bargains can be reached. Perhaps this variation explains publishers' desire to keep contract terms confidential." (Bergstrom et al. 9430) With its substantial impact on collection development, the Big Deal is still a major focal point of discussion among librarians - pros, cons, and alternatives.

We wanted to know the extent to which the Big Deal remains a key strategy for academic libraries, and its budgetary implications. We asked the participants what percentage of the collections budget is spent on Big Deals, whether via consortia or local agreements. For two 
respondents the amount was between 0 and $25 \%$; for eight respondents it was between 25 and $50 \%$, and for two respondents it was between 50 and $75 \%$. What is clear from these results is that for the majority of respondents the amount that they spend on Big Deals as a percentage of the collections budget is quite significant, and in some cases is very high. Therefore the consequences of annual price increases are becoming more and more acute, and libraries will be faced with difficult decisions in weighing the pros and cons of the Big Deal as a collection development strategy.

To drill down and obtain a more granular understanding of this situation, we asked participants about the percentage of their subscriptions or continuations budget that is spent on Big Deals. Not surprisingly, we found that the percentages were significantly higher than for the collections budget as a whole. For two respondents, the amount was between 25 and $50 \%$; for seven respondents the amount was between 50 and $75 \%$; and for one respondent the amount was even higher. This illustrates quite vividly the challenges that libraries are facing, especially when facing financial constraints and the need to reduce one's serials expenditures due to lack of adequate funding to keep up with ever-growing costs of the Big Deal. There is less and less room to maneuver, and difficult decisions to be made.

\section{Collections budget}

In our own institutions, the scope of the collections budget has expanded to include such things as discovery services, institutional memberships, metadata costs, etc. We wanted to see if this was a more general trend. Twelve of the respondents indicated that the scope has expanded, while three indicated that it has not. This indicates a clear trend among the participating libraries that the collections budget is now being used for expenditures that go beyond the traditional focus on content and resources for research and teaching. We followed this up with a question asking what type of expenditures are now being included in the collections budget. The most frequent responses were: MARC records (7); memberships (7); and discovery services (5). Other responses included interlibrary loans/resource sharing, physical processing, binding/preservation, and digitization projects. From this we can conclude that many libraries are now deploying their collections budget in diverse ways that are non-traditional, value-added, and that enhance the library's role in providing access to scholarly resources and managing a collection of increasingly digital content, while engaging with the profession through various memberships in associations (whether to support open access content or professional dialogue and collaboration).

We then asked whether this trend of expanding the scope of the collections budget is a reflection of decline in the traditional collections budget. Six of the respondents felt that this was the case, whereas two did not. One respondent felt that this shift reflects a need to support different collection efforts whereas another indicated that their decision-making was based on whether an expenditure supports collection use (such as metadata or citation management) or not. The responses as whole indicate that the collections budget is fulfilling new purposes in light of a broader approach to what is appropriate for this category of expense. It is also likely 
that these important expenses could not find funding elsewhere in the library budget, and that the collections budget was the only 'fit' that could be found. We also asked whether anything has been removed from the purview of the collections budget in recent years. All respondents indicated this was not the case, except for one who explained that WorldCat Discovery was moved to another budget line since it is focussed on management activities. The collections budget clearly faces significant pressures as different types of expenditures are being added in the digital era, while practically none are being removed.

To learn about the trend lines in financing we asked whether the collections budget has been flat, increasing, or declining in the past five years. We were heartened that eight respondents indicated that it is increasing, while four indicated that the collections budget is flat, and only two stated that it was declining. These results however should be taken with caution, since a flat budget means a significant decrease in purchasing power, and even those who have seen increases may not have received sufficient funding to keep pace with inflation in scholarly materials and demands for new resources to support new or emerging programs. Several respondents indicated that the budget had fallen for part of the time period before increasing in the last few years.

We wanted to explore this issue further, and we asked whether there is a relationship between declining budgets and new collection development practices. Specifically, we asked whether declining budgets are a cause of these practices, or whether these practices are changing regardless of budget. A range of issues and comments were raised. Three respondents mentioned the shift to DDA in order to spend monies in a more efficient and targeted manner; two respondents raised the perennial problem of inflationary pressures and the loss of purchasing power despite increases in funding; one respondent mentioned a shift in comfort from collection ownership to access; while others raised the currency exchange issue, changes in scholarship and new scholarly tools available, and reducing print purchasing for course reserves. Thus a range of strategies are employed among the respondents to address budgetary challenges and evolving collection development practices among the survey participants.

\section{$\underline{\text { Rationalizing Legacy Print Collections }}$}

Most libraries are faced with competing needs for space, and older low-use print volumes take up valuable real estate. We asked these librarians whether they were participating in any formal programs to manage the process of rightsizing collections, what they saw as challenges and opportunities in this realm, and whether this practice had been accounted for in their policies.

Of the fourteen librarians who answered this set of questions, twelve participate in at least one formal collaborative project (such as WEST). Two others stated that they intended to begin this process. Eleven participate in a journal-focused project, with the twelfth unclear. Relatively few libraries participate in a plan for monographs, though several intend to. Only three of these libraries have accounted for these projects in their collection development policies. 
Thinking about a collective collection would allow libraries to ensure dispersed preservation of the scholarly record while allowing individual libraries to withdraw materials as needed. One of the larger libraries reported that they were not discarding anything, but saw their role as one of preservation - their commitment to retain their large collection allows other libraries to confidently discard unneeded materials. Dempsey notes that, "a shared approach to print management is on the rise, and we anticipate that a large part of existing print collections, distributed across many libraries, will move into coordinated or shared management within a few years." (Dempsey et al, "Understanding the Collective Collection"). A number of collective collections initiatives have been developed in recent years, including CRL's Print Archive Network (PAN); the Western Regional Storage Trust (WEST); Eastern Academic Scholars Trust (EAST); and CRL's Print Archives and Preservation Registry (PAPR)

Librarians indicated a range of challenges and opportunities in rightsizing collections. Most felt that there were clear opportunities to free up space and to collaborate to provide access to a wider range of resources. But there are tremendous challenges, ranging from the practical (working together across different integrated library systems, developing workflows, and identifying materials to keep or discard) to the political (getting buy in from the campus community).

A few respondents indicated that the biggest challenge was in thinking about prospective collection building, so that libraries could collaboratively build a broad and dispersed collection. If libraries are to engage in collaborative collection building, then some libraries will inevitably end up making decisions for the good of the group that conflict with local needs.

\section{Demonstrating Value}

The question of the value or relevance of collection practices to our parent institutions is large and complex. It provokes much discussion at conferences, in meetings, in the professional literature, and in the corridors of libraries. We asked the participants to explain in what ways they are demonstrating value/relevance to the university administration. We also asked them to explain how this aligns with their library or university strategic plans. We received a wide range of responses. Several respondents indicated that they either don't have any current methods or are in the process of developing methods. Others raised a variety of quantitative approaches: usage data, faculty output measures, citation analysis, and cost-per-use analyses were mentioned. Qualitative approaches were also mentioned, such as communicating student success stories, developing new services to meet identified university priorities, and community engagement. Everyone expressed this as being a major challenge, and it was clear that a range of complementary strategies are employed, either quantitative, qualitative, or both.

To explore this issue further, we asked the following question - When you think about demonstrating value to the university community, are there opportunities that might lead to changes in your collection development activities and even cause you to stop doing something? Respondents gave us a number of different approaches, some specific and some general - 
critical thinking in relation to deselection and purchase of materials; focussing resources on key subject areas and what is wanted, e.g. e-access and streaming media; pay-per-view models; focusing on student success by purchasing textbooks and therefore not buying some other content; and closer forms of consortial collaboration involving a shared library services platform and shared services and workflows. It is clear that our participants are thinking about what it means to focus on new areas of activity and that this will have implications for current activities and services. As Levine-Clark has written, "Because libraries no longer have a monopoly on the provision of access to information, the value that they add to that content is now just as important as the content itself." (Levine-Clark 430)

\section{$\underline{\text { Local Digital Collections }}$}

We asked whether there were any other major trends to be thinking about in the context of collection development and one important issue came out in several responses. Digitization of local archival and special collections is, for many academic libraries, of great strategic importance. Rick Anderson argues that, "The goal is to enrich the scholarly environment with useful books and other documents that would otherwise remain hidden from scholars and students, and to shift our focus from resources and activities that make relatively little contribution to that environment to those that will have the greatest enriching effect upon it." (Anderson 8). Digitization programs allow libraries to share their unique holdings with a global audience, expanding access and increasing visibility for the institution. Yet in most cases this activity is functionally separate from collection development. As we think about the future of collection development, we must be considering how our digitization efforts fit into a cohesive collection development plan for the institution and how those plans interrelate with those from other institutions to create a global strategy.

\section{Conclusion}

Libraries are in a time of tremendous change. From time immemorial they were the primary place to gain knowledge, and now we are in an era of information abundance in which libraries compete with a huge array of sources across the internet. The small group of libraries we surveyed has responded to this change in a variety of ways.

Demand-driven acquisition allows libraries to provide access to much more than was ever possible in the print era. For users who have grown up expecting near instant access to anything they need or want, DDA helps libraries remain relevant. For most of these libraries DDA accounts for only a small portion of the overall collections budget, yet most of the librarians reported that DDA was an important part of their overall collection development strategy.

Similarly to DDA, the Big Deal allows libraries to provide access to much more than was ever possible in the past. By licensing large packages of journals, libraries can present fewer dead ends to their users, making library research a more satisfying experience. The libraries we surveyed spend a huge amount of money on big deals, making them quite risky in cases of flat or declining budgets. 
Continuing this trend of trying to provide users with more, libraries are expanding the scope of the collections budget beyond the traditional focus on content. The collections budget now funds metadata, discovery services, memberships, and resource sharing. In a networked world, it makes sense to think of the collections budget as a tool not only to acquire content, but also to help expand access to content. The focus is on developing an engagement model so that the collection is fully integrated into our users' practices, expectations, and workflows. In this context it is worth noting the words of Sheila Corrall and Angharad Roberts: "Re-evaluating the term collection, with an increasing focus on the role of "collection as process" and "collection as access", whilst not neglecting the importance of the "collection as thing", suggests an evolving role for libraries with important new dimensions. (Corral and Roberts 8)

Libraries have also taken on support for open access, through funding of article processing charges and memberships. In more cases than not, that funding comes entirely or partially from the collections budget, which makes sense when one considers that a transition to open access is expected to help ease all of the pressures put on a collections budget with an expanded scope but flat or barely increasing funding.

From a focus on the local collection, libraries have moved to a collective collection. This is perhaps nowhere more evident than in the many projects in place to collaborate on rightsizing legacy print collections. Almost all of the libraries we surveyed are participating in these projects, which allow libraries to free up space while ensuring that our cultural heritage is preserved collectively. Digitization efforts - which expand access to unique local content - also contribute to this collective collection.

Collection development policies continue to evolve as librarians are faced with this changing information landscape. Several of the libraries we surveyed have simplified or done away with policies, allowing them to be more nimble in decision-making. Others reported that they have revised policies to reflect these changing practices. It is heartening to see that these policies are allowing libraries to evolve.

Not surprisingly, in a time when the notion of the collection and of the library is in such flux, academic librarians are struggling to demonstrate value to the institution. While the librarians we surveyed clearly see a need to do this, they admit they have not done enough. Yet collection development, as outlined broadly through the activities reported in this survey, is clearly continuing to provide value to universities. We need to do a better job articulating how we have expanded access to information, how we have continued to update our collection practices to meet the needs of today's students, and how our support for open access and collaborative projects will ensure access to information long into the future. In transforming the traditional, fixed concept of a collection to a fluid model of engagement and discovery, we are recognizing the transformative changes that have occurred in our environment and among our users. 


\section{References}

Anderson, Rick. Can't Buy Us Love: The Declining Importance Of Library Books And The Rising Importance Of Special Collections. Ithaka S\&R, 2013. Web. 14 Sept. 2016. Issue Briefs.

Bergstrom, Theodore C. et al. "Evaluating Big Deal Journal Bundles". Proceedings of the National Academy of Sciences 111.26 (2014): 9425-9430. Web.

Cleary, Colleen. "Why The "Big Deal" Continues To Persist". The Serials Librarian 57.4 (2009): 364-379. Web.

Corrall, Sheila and Roberts, Angharad. Information resource development and "collection" in the digital age: Conceptual frameworks and new definitions for the network world. In: Changes in Changes in the world of electronic resources: Information and digitization. Web. 20-22 June 2012, Zadar, Croatia.

Dempsey, Lorcan, Constance Malpas, and Brian Lavoie. "Collection Directions: The Evolution Of Library Collections And Collecting". portal: Libraries and the Academy 14.3 (2014): 393-423. Web.

Fought, Rick L., Paul Gahn, and Yvonne Mills. "Promoting The Library Through The Collection Development Policy: A Case Study". Journal of Electronic Resources in Medical Libraries 11.4 (2014): 169-178. Web. 13 Sept. 2016.

Levine-Clark, Michael. "Access To Everything: Building The Future Academic Library Collection". portal: Libraries and the Academy 14.3 (2014): 425-437. Web.

Solomon, David and Bo-Christer Bjork. "Developing An Effective Market For Open Access Article Processing Charges". N.p., 2014. Web. 14 Sept. 2016. 


\section{Appendix - Survey instrument}

Q1 Does your library have a collection development (CD) policy? Yes

No

If Yes Is Selected, Then Skip To Has your library changed its CD policy...

Q2 If your library has no CD policy, why not?

Q3 Has your library changed its CD policy over the last five years?

Yes

No

If No Is Selected, Then Skip To How closely do you believe your CD practices align with your policy...

Q4 If your library has changed its CD policy over the last five years, why? How would you characterize that change?

Q5 How closely do you believe your CD practices align with your policy? Are there ways in which policy and practice do not align?

Q6 How much has your library embraced DDA and related models such as evidence based acquisition? Please list as many ways in which you use these models as possible.

Q7 Roughly what percentage of your overall collections budget goes to DDA? less than $5 \%$

$5 \%-10 \%$

$11-20 \%$

$21-30 \%$

more than $30 \%$

Q8 Has usage-based acquisition (including DDA and evidence-based acquisition) led to changes in your CD policy?

Q9 Does your library support APCs and other forms of open access investment? yes

No

If No Is Selected, Then Skip To What percentage of your collections budget is spent on journal big deals...

Q10 How much does your library spend on APCs and other forms of OA support?

Q11 Where does the funding come from to support APCs (choose all that apply) 
Collections budget

Other library funds

Funds from university external to the library

Q12 What percentage of your collections budget is spent on journal big deals (whether via consortia or local arrangements)?

Q13 What percentage of your subscription budget is spent on journal big deals (whether via consortia or local arrangements)?

Q14 Has the scope of the collections budget expanded (to include discovery services, memberships, metadata, etc.)?

Yes

No

If No Is Selected, Then Skip To Has anything been removed from the scope of the collections budget...

Q15 What is being included now in this expanded collections budget?

Q16 Given this trend of expanding the scope of the collections budget, is the traditional collections budget declining?

Q17 Has anything been removed from the scope of the collections budget?

Q18 Thinking of the past five years, is the collections budget flat, increasing, or declining? Flat Increasing

Declining

Q19 What do you see as the relationship between declining budgets and new collection development practices at your institution? Are declining budgets a cause of these practices? Are these practices changing regardless of budget?

Q20 To what extent is your library participating in projects that are designed to "rightsize" legacy print collections through collaborative planning for deaccessioning? (projects such as EAST or WEST)

Q21 Are these projects to manage legacy print collections accounted for in your CD policy? Yes

No

Q22 What are the challenges/opportunities for rationalizing print collections in a highly collaborative way, eg harmonizing practices, workflows, access/delivery of materials? 
Q23 In what ways are you demonstrating value/relevance to the university administration? Please indicate how this aligns with library or university strategic plans.

Q24 When you think about demonstrating value to the university community, are there opportunities that might lead to changes in your CD activities and even cause you to stop doing something?

Q25 Are there any major trends in collection development that are impacting your institution and which are not reflected in our questions and your answers?

Q26 To help us with tracking, please enter your name and institution. We will not identify you or the institution in any way in the article. 